\title{
Trauma Leaves Children Behind: Impact of Psychological Distress on Children's Learning
}

Messo IN ${ }^{*}$

Open University of Tanzania, Tanzania

*Corresponding author: Innocent Nasson Messo, Open University of Tanzania, Box 23409, Dar es Salaam, Tanzania, Tel: 255784 490 389 ; E-mail: innocent.messo@out.ac.tz

Rec date: Mar 21, 2014; Acc date: Apr 25, 2014; Pub date: Apr 27, 2014

Copyright: (C) 2014 Messo IN. This is an open-access article distributed under the terms of the Creative Commons Attribution License, which permits unrestricted use, distribution, and reproduction in any medium, provided the original author and source are credited

\begin{abstract}
Tanzania has been prone to both natural and man-made disasters such as droughts, floods, accidents, earthquakes, and locus invasions. These disasters affect livelihoods; destroy infrastructure, cause food shortages and health problems. The Uncontrolled explosions of bombs on 29th April 2009, at the Tanzania People's Defence Forces (TPDF) armouries in Mbagala military facility, in Dar es Salaam must have been a terrible experience, with psychological as well as physical consequences. The purpose of this study was to investigate the psychological effects of bomb blasts on academic development among the children involved in the tragedy. It was put forward that the studied children would exhibit psychological disorders resulting from bombs blasts, and such disorders would have impact on their learning. This study was qualitative in nature, and purposive sampling was applied in selecting both students and teachers for the study. The study was conducted in the two primary schools (Maendeleo and Mbagala Kuu) that are too close to the military base where the bombs exploded. It was found that bombs blasts had caused intrusive thoughts, frustrations and low confidence to the children, which in turn affected their academic performance, mainly in mathematics and science subjects. The study suggests that these children should be supported just as it is for students with special educational needs.
\end{abstract}

Keywords Man-made disasters; Embassy bombing; Behavioral alterations

\section{Introduction}

Tanzania has been a victim of several stressful events ranging from natural to manmade. There have recently been cases of bombs blasts which like other events have been very stressful, particularly to children. On April 29 2009, there were uncontrollable blasts of military bombs at the Tanzania People's Defence Forces (TPDF) premises in Mbagala-Dar es Salaam. This was a serious and dangerous event in the current history of the country, as it claimed the lives of 26 people, about 600 others injured and destroying about 9049 homes and other properties [1-4].

There was yet another bombs tragedy on 16th of February 2011 from one of the Tanzanian army base in Gongo la Mboto, Dar es Salaam (military camp NO: KJ511), that led to many people being displaced or affected in one way or another. Continuous explosions caused panic and horror that made almost everybody flee in all directions from their residences to unknown destinations, but it was all meant to find a safe place in order to save their lives. Many people were injured while running away and about 22 people lost their lives [5] and the most victims as usual were women, children and elders.

There have been also violent events (linked with terrorism) in the country coloured with religious and political motives whereby people, including children have lost lives and property, while some remain grievously wounded. Tanzania had not been targeted by terrorists or such terrible events since the US embassy bombing in 1998. Thus, the explosion of 5th May 2013 was the first large-scale attack which occurred at a place of worship in the country. At least 2 people were killed and dozens wounded in, when a Catholic parish in Arusha, Tanzania was bombed during its inauguration ceremony [6].

Again, three people were killed and about 60 others seriously injured after bomb explosions rocked a political rally in Arusha on 15 June 2013 (Daily News 2013) [6,7]. In all these bomb related events, this paper is focused on the Mbagala bombs blasts.

\section{Effects of Trauma on Children's Learning}

Research documenting the effects of trauma on learning has become increasingly available and consistent in its descriptions of the cognitive and behavioral alterations following exposure to trauma. From early infancy through adulthood, trauma can alter the way we view ourselves, the world around us, and alter how we process information and the way we behave and respond to our environment [8].

A traumatic event can, seriously interrupt the school routine and the processes of teaching and learning [9]. There are usually high levels of emotional upset, potential for disruptive behaviour or loss of student attendance unless efforts are made to reach out to students and staff with additional information and services. Students traumatized have been shown to have lower grade point averages, more negative remarks in their cumulative records, and more reported absences from school than other students. They may have increased difficulties concentrating and learning at school and may engage in unusually reckless or aggressive behaviour.

According to [10] traumatized children may experience barriers in several school-related areas ranging from academic performance, classroom behaviour, and relationships. Examples of the academic performance potential factors include: disruption of language and 
communication skills, difficulty organizing narrative material comprehension of cause-and-effect relationships, difficulty with taking another person's perspective, trouble with attending to classroom tasks, barriers with self-regulating or modulating emotions, and reduced motivation for academic engagement. Trauma also affects self-regulation, social skills and a child's sense of health and wellbeing, along with interfering with more traditional academic skills that require language, memory and executive function [10]

Following exposure to a potentially trauma-inducing incident, survivors may become frozen in an activated state of arousal. Shortterm and prolonged arousal can affect cognitive and behavioral functions. In the arousal state, changes in the brain are triggered by a variety of stress related functions [11,12]. If a child/student who has been traumatized remains in an aroused state of fear and finds it difficult to process verbal information, it then becomes difficult to follow directions, to recall what was heard, to make sense out of what is being said. Focusing, attending, retaining and recalling verbal information becomes very difficult. These are primary learning functions that can be altered during or immediately following traumatic exposure and for some continue unrecognized for long periods.

Cognitive deficits such as poor problem solving, (unable to think out or make sense of what is happening), low self-esteem (how one thinks of oneself) and hopelessness (loss of future orientation) have all been clearly linked to negative (traumatic) life events. The fact is, trauma has been shown to significantly compromise cognitive development [13-17].

Previous studies in the same study area have shown several effects of trauma on children. A study conducted by Messo [18] on the prevalence of Post-Traumatic Stress Disorder (PTSD) among the children victims of Mbagala bombs blasts showed that $92.8 \%$ of the children exhibited PTSD symptoms. After one year, Messo [19] studied other psychological disorders than PTSD (in the same study area and the same population) whereby $60.3 \%$ children were found with different psychological problems ranging from somatisation, obsessive-compulsive, interpersonal sensitivity, depression, anxiety, hostility, phobic anxiety, psychocism and paranoid ideation. This study therefore dealt with the effects of traumatic experiences on the children's school learning.

\section{Methods}

The study was conducted at Mbagala Kuu and Maendeleo primary schools as the two schools are closer to the Tanzania Peoples Defence Force; a military base from which the bombs exploded. The study is qualitative in nature. Purposeful sampling was employed to recruit students for Focus Group Discussions and interview for teachers. Older children (standard six to seven) were selected to increase the likelihood that their cognitive development, language and the ability to remember were adequate to participate to the discussions. A total number of students were 48, and six teachers for interview (two academic masters-one from each school, and four class teachers- two from each school).

\section{Instruments}

Two instruments were employed in this study. The first was a focus group discussion guide (FGD) which was administered to the children victims of the bombs. The instrument was aimed at capturing the learning process, before and after the event and challenges that participants' experienced after a traumatic situation. Focus Group Discussions consisted of eight participants per group, which formed six groups; three from each school.

The second tool was interview guide. This was meant to explore the performance of learners from the two schools' academic masters and class teachers, tracing the trend of learners' academic performance in relation to the traumatic situation they experienced. Both instruments were translated into Kiswahili (the national language of Tanzania) by the National Council of Kiswahili (BAKITA) so that participants could participate with confidence. The Kiswahili version was back-translated into English by the same firm to ensure that the original content had not been altered.

\section{Analysis}

Thematic analysis approach was employed in the analysis of data from Focus Group Discussions and interviews, in which emerging themes were identified and directly linked to the objective of the study. The following thematic steps were followed: familiarisation with data, generating initial codes, searching for themes, reviewing themes, defining and naming themes and producing the report. All the collected data were transcribed and translated into English for the purpose of report writing.

\section{Results}

The key objective of this study was to investigate the learning difficulties, if any, related to bombs blasts in the study area. In order to establish the effects, participants were first asked whether they still remembered the event (do you remember the bombing event that happened nearby your school?). All participants from both schools acknowledged to have remembered the event. One student from Maendeleo Primary School said;

"You know what? I will never forget those bombs. I just ran from here (school) to a place which I didn't even know, just to be collected by one old woman who took me to her house before I told her to take me back to school, so that my teachers could send me home. I was completely out of my mind for some days".

Participants were able to recollect their memories about the atmosphere of that day, what had happened to them and their relatives. This fact is supported by Van der Kolk (1994) [20] who contends that some people say they are "haunted" by memories of traumatic experiences which intrude on and disrupt their daily lives. They often cannot get the "pictures" of the trauma out of their heads. They may have recurring nightmares, "flashbacks," or they may even relive the trauma as if it was happening in present time. Complementing this contention, the academic master from Mbagala Kuu School, asked whether he thought students remembered the event, and said that;

"No one can forget such a stressful event; we could not see each other there. All students were scattered in all directions, without knowing even where they were heading to. My kid is also a student in this school, but it took me two days looking for her, just to find her in one of the churches at Temeke Street".

A standard seven class teacher from the same school also had the following;

"Up to this moment in my class I still hear a lot about those bombs, and this occurs in most cases when students have free time; be in 
classroom or outside the classroom. Sometimes they take as jokes, trying to recall the way people were scattered, others climbing trees, and whatever happened on that day. This shows these students really remember the event".

The second question was intended to explore whether students had perceived their lives differently after the event (since that day, how do you perceive the life here at school, at home and other areas?). Some participants from both schools agreed to have changed their perceptions about living. They reported that the bombs had taught them a very important lesson; being cautious on whatever they do. One student from Maendeleo School shared her experience on how the event had changed her life perception;

"Since I had never encountered such kind of event before, the bombs have shown me that this world is not a safer place to live at all. Nowadays I'm very careful with what I do and where I go. It's like I live in Somalia or Ethiopia where I hear that these things are normal".

Changes in life perception among students were mainly found in their social life, when interacting with peers. Under this parameter, there were those who said that the event had limited their social interactions. They could neither go to play with their peers in open spaces nor walk around some interesting places like beaches, as one participant from Mbagala Kuu school was quoted that;

"I was told by my parents that the bombs were scattered all over after the explosions. Since then I never go to places that I used to go before, like playing in our school premises, visiting some of my relatives who live distant from my home and other communal places".

Teachers also admitted to have noted some minor changes in the lives of few students. It was reported that some students who were so active and talkative in and outside classrooms had been muted by the tragedy; particularly those who were directly victimized like losing their loved ones. A standard six teacher from Maendeleo School had the following to say;

"There were two cases of students who lost their parents in the event in my School. One does not even go to play with his peers the way he used, while the other one is always isolating herself from others even in the classroom. I also get the same reports from some parents that their kids have changed. One of the parents told me that he thought his boy was sick, but when he took him to the hospital, nothing was found'.

The key question for this study was whether the trauma had any impact in the children's learning, which in turn could affect their academic performance. Students from both schools revealed a number of effects of trauma on their learning process. The major problem identified was intrusive thoughts which were reported to interfere with classroom concentration. Participants reported the increased interference of the event (bombs blasts) and its effects to their thoughts, reminding them of what happened on that day. This lowered down the learning process among students, as one of them from Mbagala Kuu School said;

"I try very hard to concentrate on my subjects but the pictures of our destroyed house keep coming in my mind. I feel like keep talking to my friends always because when I remain alone the situation becomes worse. The strangest thing is that I used to recall what I study at nights when I want to sleep, but nowadays I only get the images of the event and what followed after it".
This fact was highly supported by the class teachers from both schools, especially in the first two years after the event. The class masters reported that it was very hard for them to control classes and attract attention from students. Students were always sensitive about the school surroundings, even in classrooms and offices. According to Mbagala Kuu class master, students were always pre-occupied with their safety issues, than concentrating with learning;

"Currently the situation is a bit good compared to the first two years after the event. It was very hard to control them, and the worst side of it is that the school is too close to the military base. Students, and some teachers to be frank, were hyper sensitive to the environment. A very minute explosion-like sound would cause a lot of disturbances, but now, at least things are running in a proper direction".

Frustrations were also reported to affect the learning process among the bombs victim students. Some of them who used to score high before became frustrated with their perceived lack of progress and few were inclined to give-up. One student from Maendeleo School reported to have lacked presence, often dissociating, daydreaming and appearing to "switch off" from classroom activities;

"I don't feel like doing anything in the class, I have lost hope because my family is scattered and my father is badly injured. I don't know but I think that I'm finished because I can't score my subjects the way I used any more. I'm finished, completely finished'.

Frustrations among the studied participants were accompanied by lack of confidence, as [23] contend that self-belief is the cornerstone of anybody's ability to learn. As a result of Mbagala bombs blasts, majority of learners reported lack of confidence in themselves and their academic ability. Some of them who had consistent academic performances before became a bit poor after the event. Observations form Maendeleo School showed that there were students who looked like confused, irritating and showing antisocial behaviors (isolating oneself from peers, hostility and aggression). "It took different periods of time for them to come into their normal state, others (very few) up to the moment still look frustrated", added the academic master. It was also reported that some students had dropped out of schools after the event when they lacked guidance from their families and teachers as well.

The most negative impact of trauma was reported to those subjects that demand high concentration (e.g. mathematics and science subjects), compared to subjects like religion and arts. Sports had become more difficult, especially for those who were physically injured. Consistent with the experience that schoolwork had become more difficult was the finding that exam results, and consequently grades, had gone down as it was reported by both schools' Academic Masters. One of them (from Maendeleo School) said;

"I can talk of about ten children that I knew were good in mathematics and some are in your sample, but I wondered what had happened to them. We tried to give them some more time to recover from thinking the event. We tried very hard to encourage them to settle their thoughts, and for some I also talked to their parents to be close to them so that they uncover what is covered in their minds".

Many studies have pointed out how trauma results in a series of negative consequences for young people's learning ability [21]. The experience of safety is the basis for active exploration, while traumatized children have a tendency to react to novel information and stimuli either with exaggerated physiological activation or dissociative states. These reaction patterns can be understood as a kind 
Page 4 of 5

of defense rooted in a basic experience of the world as an unsafe place where safety is sought in what is known and new situations or information are avoided.

\section{Discussion}

Schooling is an investment in the future, not only for the individual student but also for society at large. Just as reduced work performance has personal and economic consequences both for the individual and the company that a person works for, a decline in school performance represents a loss of potential for the individual student and society.

The findings of the current study on children's exposure to trauma and its academic effects are in line with other studies on trauma and psychological wellbeing in children. Yule and Gold (1993) [10] emphasized the loss of motivation in their study of survivors of a maritime disaster. Following such events, children may pose the question: 'What is the use of investing in school when you can be dead tomorrow?' Yule and Gold (1993) [10] found a decline in academic performance in the survivors of the sinking of the cruise ship Jupiter in the year following the disaster. When they compared the end of year exam results for three years before the disaster with the end of term results 10 months after the sinking, they found that the accident had a significant effect on the students' performance (about half a z-score). This effected persisted through the following year and resulted in lower examinations grades than had been originally predicted.

Following a discotheque fire in Goteborg, Sweden, where 400 young people were present, 63 young people were killed and 213 injured. About two years after the fire, surviving adolescents were interviewed and answered questionnaires about their experiences during and following the fire. It was shown that the trauma had a significant impact on their school performance [20]. In all, $23 \%$ of the victims (girls 19\%, boys 27\%) indicated that they had either dropped out of school because of the fire or that they had to repeat a class.

In a study of children who had been exposed to trauma (community violence), also found that there was a suggested link between trauma severity and school performance. Group members whose posttraumatic stress disorder scores fell in the 'severe' to 'very severe' range had a significantly lower mean Grade Point Average (GPA) than members whose scores fell in the moderate range [21].

\section{Conclusion}

Traumatic events have been shown to affect children psychologically in the same way or more than adults. Literature has shown that traumatic experiences have a significant impact on children's learning. Children under this study reported to have changed their living modalities fearing the same to happen again. Intrusive thoughts were reported to be the leading impact of bombs blasts to the studied children. The thoughts affected their classroom concentration which in turn, affected their academic performance. The current study therefore concludes that the Mbagala bomb blasts were a serious event that affected the academic life of children. How students process trauma depends on their age and level of development. By understanding how students experience traumatic events, and how they express their lingering distress over the experience, school personnel can better respond and help them through such challenging time.

\section{Recommendations}

Children and adolescents that experience trauma have been found to experience difficulties in learning. The reasons for this are still unclear but trauma affects attention and memory. While students with identified special educational needs may benefit from educational methods that are tailor-made for them and from individual support, educational strategies for traumatized students are not readily available in Tanzania. It is important to continue to document the educational consequences of trauma but the evidence is already sufficient to warrant the development of better educational strategies by policy makers to help the many students that annually experience such events.

It is also important that those who develop psychological disorders get appropriate help through trauma-specific intervention. Although there is a lack of research on the efficacy of post-traumatic therapy in children, cognitive-behavioral therapy including exposure therapy, and eye movement desensitization and reprocessing, well documented as beneficial methods for adults, can greatly reduce post-traumatic problems in younger age groups as well as directly targeting their problems [22].

Written emotional expression of one's trauma has been very successful in producing beneficial health results, and has recently been used in schools as an intervention for asthma with effective results [23]. By letting traumatized students write about their innermost thoughts and feelings concerning the traumatic event three to five times for 20 minutes, the educational psychologist may administer this as a self-help method for children and adolescents following trauma.

\section{References}

1. Janoff-Bulman R. (1992). Shattered assumptions: toward a new psychology of trauma. New York, NY: Free Press.

2. Joseph S (2009) Lukuvi receives Dar bombs blast report. The African.

3. Kimaro S (2009) Mbagala tragedy: a lesson on disaster management. This Day, pp. 18.

4. Machira P (2009) Government to release Mbagala blasts report this week. The Guardian, pp3.

5. Onyango E (2011) The Gongo La Mboto bomb blast that caused panic, fear, great horror and sorrow to the people around.

6. Schneible A (2013) Catholic Parish in Arusha Bombed.

7. Daily News Newspaper (2013) Tanzania: Bombs Rock Political Rally in Arusha.

8. Anderson, T (2005). PTSD in children and adolescents. Illinois: Great Cities Institute Publication.

9. Hamblen, J (2005). PTSD in children and adolescents. A national center for PTSD fact sheet.

10. Yule W, Gold A (1993) Wise before the event: Coping with crises in schools. London, Calouste Gulbenkian Foundation.

11. van der Kolk BA (1994) The body keeps the score: memory and the evolving psychobiology of posttraumatic stress. Harv Rev Psychiatry 1: 253-265.

12. van der Kolk B A (1987). The psychological consequences of overwhelming life experiences. Journal of Clinical Psychology, 58, 16-24.

13. Armsworth M, Holaday M (1993). The effects of psychological trauma on children and adolescents. Journal of Counseling and Development, 72: 49-56.

14. Schwartz D, Gorman A H (2003). Community violence exposure and children's academic functioning. Journal of Educational Psychology 95 163-173. 
Citation: Messo IN (2014) Trauma Leaves Children Behind: Impact of Psychological Distress on Children's Learning . J Trauma Treat S4: 0013. doi:10.4172/2167-1222.S4-013

Page 5 of 5

15. Pellegrin A L (2009). The role of hurricane exposure and life disruption as predictors of child post-traumatic stress symptomatology following hurricane Katrina. PhD Dissertation, Louisiana State University.

16. Perrin S, Smith P, Yule W (2000) The assessment and treatment of Posttraumatic Stress Disorder in children and adolescents. J Child Psychol Psychiatry 41: 277-289.

17. Seedat Nyamai, Vythilingum (2004). An overview of post- traumatic stress disorder in children and adolescents. Journal of Primary Care Psychiatry, 6: 43-48.

18. Messo I (2012) Prevalence of Posttraumatic Stress Disorder in Children Involved Bombs Blasts in Mbagala-Tanzania in April 2009. J of Health Psychology.

19. Messo I (2013) Psychological Effects of Mbagala Bombs Blasts in Children. J Health Psychol 18: 627-637
20. Broberg AO, Dyregrov A, Lilled (in manuscript). The Goteborg discotheque fire: Posttraumaticstress, school adjustment and satisfaction with services offered by the primary victims one year later.

21. Saltzman W R, Pynoos R S, Steinberg A M, Eisenberg E, Layne C M (2001). Trauma and grieffocused intervention for adolescents exposed to community violence. Group Dynamics: Theory, Research \& Practice, 5: 291-303.

22. Cohen J, Mannarino, A, Berliner L, Deblinger E (2000) Trauma-focused cognitive behavioral therapy for children and adolescents. Journal of Interpersonal Violence, 15: 1202-1223.

23. Bray MA, Lea AT, Patwa SS, Margiano SG, Alric JM et al. (2003) Written emotional expression as an intervention for asthma. Psychology in the Schools 40: 193-207. 